\title{
Tinjauan Wisata Halal Prespektif Maqosidus Syariah Terkait Fatwa Dsn Mui Dsn-Mui No. 08 Tahun 2016
}

\author{
Muhammad Nizar, Antin Rakhmawati \\ Universitas Yudharta Pasuruan \\ muhammadnizar@yudharta.ac.id, antinrakhmawati@gmail.com
}

\begin{abstract}
We must support halal tourism in the development of the sharia banking industry in Indonesia, in order to uphold the existence of sharia economics in Indonesia. The method used in this article is descriptive. With the results of the study that the concept of halal tourism perspective maqasidus sharia is classified as a tigan including Dzaruriyah, Hajiyah, Tahsiniyah. Halal tourism practitioners have challenges in developing their business. Among them there is business development in the tourism sector which is considered prospective in the future, but on the other hand they are committed to facilitating the needs of tourists not to abandon their obligations to worship God and ignore their teachings. This is a picture that will show that in order to develop a halal tourism industry, however, one must prioritize its most basic human characteristics, including providing protection to the tourist religion as taught in the Maqashid al-Shariah which will be further reviewed in subsequent studies. In connection with maqashid al-shariah. And in this study will be explained about the view of halal tourism in DSN-MUI No. 08 of 2016.
\end{abstract}

\section{Keywords: Halal tourism, Maqashid al-syariah.}

\section{A. PENDAhULUAN}

Kesadaran akan produk halal di Indonesia belakangan ini semakin meningkat, ini menunjukkan peningkatan di sektor industri halal, diantaranya munculnya halal tourism. Samori, Md Salleh, \& Khalid, (2016), Mohamed Battour, Mohd Nazari Ismail, \& Moustafa Battor, (2012) dalam penelitiannya menunjukkan beberapa tahun ini wisatawan muslim peduli terhadap konsumsi produk dan layanan yang sesuai dengan syariah. (Crescentrating, 2017) memprediksi pada tahun 2020 industri halal akan meningkat 20 persen dan memiliki pengaruh peningkatan nilai pengeluaran pemerintah hingga 200 milyar USD.

Untuk meningkatkan potensi pariwisata halal, banyak beberapa daerah mulai menyediakan fasilitas, seperti infrastruktur, SDM, serta manajemen pengelolaannya. Namun sayangnya beberapa pariwisata yang ada di Indonesia masih mendapat kendala dalam pemahaman terkait wisata halal. Menurut Salehudin \& Luthfi, (2011) wisata halal adalah pariwisata yang ditujukan untuk wisatawan muslim dan pelayanan merujuk pada aturan Islam. Artinya, pemerintah akan melarang aktor-aktor pariwisata 
menjajakan minuman yang mengandung genre-genre yang berbau non-islam, menyediakan fasilitas yang terpisah antara laki-laki atau perempuan yang non-muhrim (bukan suami-isteri).

Perkembangan wisata halal berawal dari adanya jenis wisata ziarah atau religi (pilgrims tourism / spiritual tourism). Pada tahun 1967 telah dilaksanakan konferensi di Cordoba, Spanyol oleh World Tourism Organization (UNWTO) dengan judul "Tourism and Religions: Contribution to the Dialogue of Cultures, Religions and Civilizations" (UNWTO, 2011 dalam Pariwisata, 2012). Wisata ziarah meliputi aktivitas wisata yang didasarkan atas motivasi nilai religi tertentu seperti Hindu, Budha, Kristen, Islam, dan religi lainnya. Seiring perkembangan zaman, fenomena wisata tersebut tidak hanya terbatas pada jenis wisata ziarah, namun berkembang ke dalam bentuk baru nilai-nilai yang bersifat universal seperti kearifan lokal, memberi manfaat bagi masyarakat, dan unsur pembelajaran. Dengan demikian bukanlah hal yang mustahil jika wisatawan muslim menjadi segmen baru yang sedang berkembang di arena pariwisata dunia (Pariwisata, 2012).

Dilihat dari sudut pandang demografi, potensi wisatawan muslim dinilai cukup potensial, karena secara keseluruhan jumlah penduduk muslim dunia sangat besar seperti Indonesia, Malaysia, Brunei Darussalam, Turki, dan negara- negara Timur Tengah dengan tipikal konsumen berusia muda atau usia produktif, berpendidikan, dan memiliki pendapatan yang besar. Menurut Databox, bahwa jumlah penduduk muslim dunia pada tahun 2019 sebesar 7,7 miliar. Jumlah penduduk muslim tersebut merupakan urutan pertama (Pariwisata, 2019).

Tujuan syariat adalah mencapai kemaslahatan baik lahir maupun batin, dunia maupun akhirat, untuk kepentingan diri maupun sosial lain. Ini menunjukkan bahwa karater ajaran Islam menekankan pada adanya keseimbangan (tawazun-balance) di kalangan umatnya. Seorang muslim tidaklah dapat dibenarkan jika dalam hidupnya hanyalah mengejar kepentingan keduniawian, sementara kepentingan akhiratnya diabaikan, atau bahkan ditinggalkan (A. R. A. Rakhmawati, 2016). Padahal dalam Islam, keduanya haruslah sama-sama mendapatkan perhatian secara berkeseimbangan. Bukankah kehidupan dunia hanyalah sesaat, karena kehidupan akhiratlah yang kekal dan abadi sebagai tempat mempertanggungjawabkan segala perbuatannya selama di dunia.

Selanjutnya dalam kaitan dengan destinasi wisata halal, bahwasanya wisatawan itu bagaikan tamu yang bersilaturrahim kepada sebuah keluarga. Karena itu mereka perlu dihormati kedatangannya dan dilindungi segala kepentingannya agar merasa mendapat kepuasan lahir dan batin dalam melakukan kunjungan (Sofyan, 2012). Di dalam filosofi budaya Jawa, penghormatan seorang tuan rumah terhadap setiap tamu yang datang tersimpul di dalam ajaran, yakni gupuh, lungguh dan suguh. Gupuh dimaksudkan agar tuan rumah segera menyambut baik tamunya dengan penuh hormat dan ramah, setelah itu sang tamu dipersilakan duduk, dan jika memungkinkan bisa dijamu dengan sekadar makanan dan minuman seperlunya (Bawazir, 2013). Dari latar 
belakang inilah maka penting untuk menulis artikel dengan judul tinjauan wisata halal prespektif maqosidus syariah.

Praktik semacam itu sejatinya termuat dalam ajaran Islam yang mewajibkan setiap Muslim agar memuliakan tamunya sebagai ekspresi rasa keimanan mereka kepada Allah Swt (Syarifuddin, 2009). Selanjutnya bagaimanakah bentuk penghormatan dan pelayanan itu jika diaplikasikan ke dalam dunia wisata dalam perspektif maqashid al-syariah yang pada dasarnya mengajarkan untuk melindungi kepentingan wisatawan yang meliputi aspek: agama, jiwa, akal, keturunan, harta milik, dan bahkan juga lingkungan sekitarnya (Masyfuk Zuhdi, 1987).

\section{B. KAJIAN PUSTAKA}

\section{Pariwisata Halal}

Dalam Kamus Besar Bahasa Indonesia, Pariwisata adalah berhubungan dengan perjalanan untuk rekreasi; pelancongan (Hasan Alwai (KBBI) Kepala pusat Bahasa, 2003). Sedangkan menurut Undang-undang Nomor 10 tahun 2009 terkait Kepariwisataan, wisata adalah kegiatan perjalanan yang dilakukan oleh seseorang atau sekelompok orang dengan mengunjungi tempat tertentu untuk tujuan rekreasi, mempelajari keunikan daya tarik, pengembangan pribadi yang dikunjungi dalam jangka waktu tertentu (Battour \& Ismail, 2016). Pariwisata adalah berbagai macam kegiatan wisata dan didukung berbagai fasilitas, layanan yang disediakan oleh masyarakat, pemerintah, pengusaha, dan pemerintah daerah (Permadi, Darwini, Retnowati, Negara, \& Septiani, 2018).

Makna pariwisata halal mungkin akan berbeda-beda bagi setiap orang. Ada yang mengartikan sebagai penyajian makanan dari bahan-bahan yang halal atau aturan perwisataan yang mengikuti tata cara dalam syari'at Islam (Salehudin \& Luthfi, 2011) (Pilliang, 2012). Dalam konteks "tourism", di satu sisi, kata "wisata" merupakan arena/tempat untuk menghabiskan waktu senggang, berlibur atau hanya ingin menikmati keindahan alam. Selain itu, kata "halal" adalah istilah yang sangat erat dengan relasi kehidupan orang-orang Islam, selalu dikultuskan dan dikaitkan dengan ajaran agama dan dalam kitab suci umat Islam. Wisata halal bermakna industri pariwisata yang ditujukan untuk wisatawan muslim dan pelayanan merujuk pada aturan Islam. Artinya, pemerintah akan melarang aktor-aktor pariwisata menjajakan minuman yang mengandung genre-genre yang berbau non-Islam, menyediakan fasilitas yang terpisah antara laki-laki atau perempuan yang non-muhrim (bukan suami-isteri).

Istilah wisata halal sudah menjadi trend di berbagai dunia seiring perkembangan teknologi yang berkembang sangat cepat. Istilah wisata halal dalam literatur pada umumnya disamakan dengan beberapa istilah seperti syari'ah tourism, Islamic tourism, halal friendly tourism destination, halal travel, halal lifestyle, friendly travel destinations. Dari sisi industri, wisata halal merupakan suatu produk pelengkap dan tidak menghilangkan jenis pariwisata konvensional. Sebagai cara baru untuk 
mengembangkan pariwisata Indonesia yang menjunjung tinggi budaya dan nilai-nilai Islami tanpa menghilangkan keunikan dan orisinalitas daerah (Andriani, 2015).

Wisata halal sebagaimana disosialisasikan dalam Indonesia Halal Expo (Indhex) 2013 dan Global Halal Forum yang digelar pada 30 Oktober - 2 November 2013 di Gedung Pusat Niaga, JIExpo (PRJ), Jakarta (Rabu, 30/10/2013), President Islamic Nutrition Council of America, Muhammad Munir Caudry, menjelaskan bahwa, "wisata halal merupakan konsep baru pariwisata. Ini bukanlah wisata religi seperti umroh dan menunaikan ibadah haji. Wisata halal adalah pariwisata yang melayani liburan, dengan menyesuaikan gaya liburan sesuai dengan kebutuhan dan permintaan traveler muslim". Dalam hal ini hotel yang mengusung prinsip syariah tidak melayani minuman beralkohol dan memiliki kolam renang dan fasilitas spa terpisah untuk pria dan wanita (Wuryanti, Andrijono, Susworo, \& Witjaksono, 2015).

Dalam pandangan Islam, pertama, perjalanan dianggap sebagai ibadah, karena diperintahkan untuk melakukan satu kewajiban dari rukun Islam, yaitu haji pada bulan tertentu dan umrah yang dilakukan sepanjang tahun ke baitullah. Kedua, dalam pandangan dunia Islam, wisata juga terhubung dengan konsep pengetahuan dan pembelajaran. Hal ini menjadi perjalanan terbesar yang dilakukan pada awal Islam dengan tujuan mencari dan menyebarkan pengetahuan (QS. al-Taubah: 112).

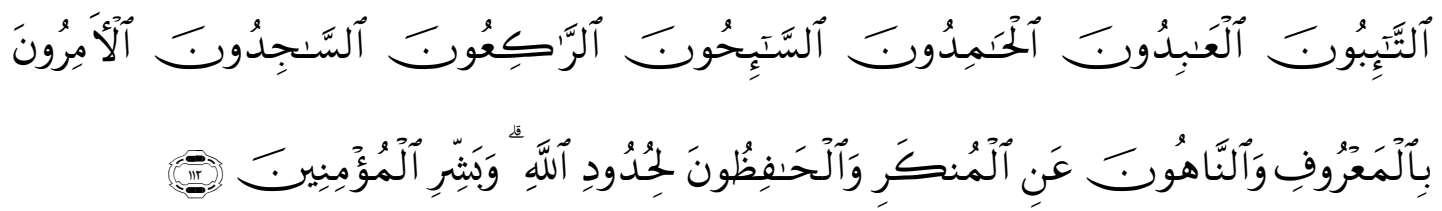

Artinya: Mereka itu adalah orang-orang yang bertaubat, yang beribadat, yang memuji, yang melawat, yang ruku', yang sujud, yang menyuruh berbuat ma'ruf dan mencegah berbuat Munkar dan yang memelihara hukum-hukum Allah. dan gembirakanlah orang-orang mukmin itu. (QS. al-Taubah: 112)

Ketiga, tujuan wisata dalam Islam adalah untuk belajar ilmu pengetahuan dan berpikir. Perintah untuk berwisata di muka bumi muncul pada beberapa tempat dalam Al-Qur'an surat al-An'am: 11-12 dan al-Naml: 69-70.

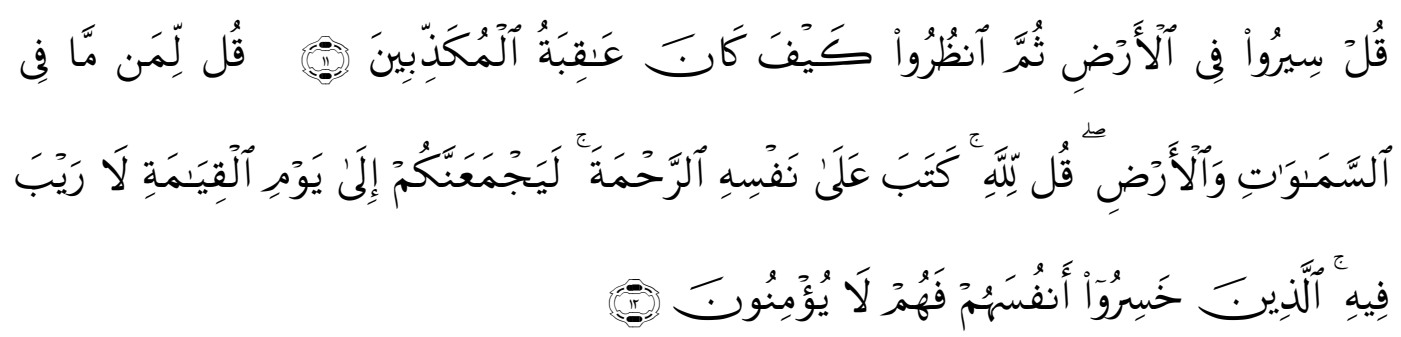

Artinya: 11. Katakanlah: "Berjalanlah di muka bumi, kemudian perhatikanlah bagaimana kesudahan orang-orang yang mendustakan itu." 12. Katakanlah: "Kepunyaan siapakah apa yang ada di langit dan di bumi." Katakanlah: "Kepunyaan Allah." Dia telah menetapkan atas Diri-Nya kasih sayang. Dia 
sungguh akan menghimpun kamu pada hari kiamat yang tidak ada keraguan padanya. orang-orang yang meragukan dirinya mereka itu tidak beriman. (QS. al-An'am: 11-12)

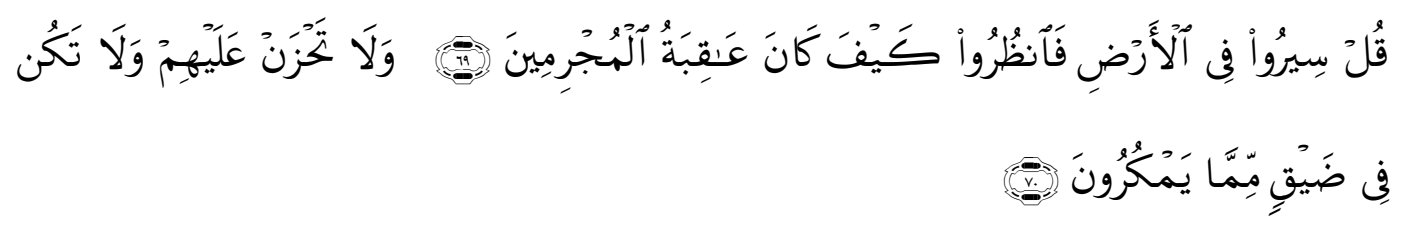

Artinya: 69. Katakanlah: "Berjalanlah kamu (di muka) bumi, lalu perhatikanlah bagaimana akibat orang-orang yang berdosa. 70 . dan janganlah kamu berduka cita terhadap mereka, dan janganlah (dadamu) merasa sempit terhadap apa yang mereka tipudayakan". (QS. al-Naml: 69-70)

Keempat, tujuan terbesar dari perjalanan dalam wisata Islam adalah untuk mengajak orang lain kepada Allah dan untuk menyampaikan kepada umat manusia ajaran Islam yang diwahyukan kepada Nabi Muhammad saw. Hal ini adalah misi Rasul dan para sahabat beliau.

Dari sudut pandang syariah Islam, aktivitas pariwisata diarahkan sesuai dengan prinsip ta'aruf (saling mengenal), tabadul al-manafi (pertukaran manfaat), dan ta'awun wa takaful (saling menolong dan saling menanggung risiko) (Pradja, 2012). Dalam Islam, prinsip ini dirumuskan dalam terma ta'aruf sesuai dengan al-Qur'an surat al-Hujurat ayat 13:

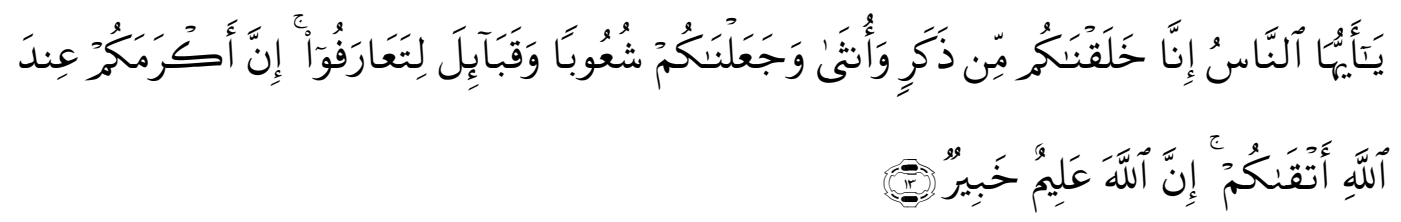

Artinya: Hai manusia, Sesungguhnya Kami menciptakan kamu dari seorang laki-laki dan seorang perempuan dan menjadikan kamu berbangsa-bangsa dan bersuku-suku supaya kamu saling kenal-mengenal. Sesungguhnya orang yang paling mulia diantara kamu disisi Allah ialah orang yang paling taqwa diantara kamu. Sesungguhnya Allah Maha mengetahui lagi Maha Mengenal.

(QS. Al-Hujurat: 13)

Para sahabat Nabi Muhammad menyebar ke seluruh dunia, mengajarkan kebaikan dan mengajak mereka untuk menjalankan kebenaran. Konsep wisata dikembangkan untuk mencapai tujuan tersebut. Akhirnya, wisata Islam juga termasuk kegiatan perjalanan untuk merenungkan keajaiban penciptaan Allah dan menikmati keindahan alam semesta ini, sehingga akan membuat jiwa manusia mengembangkan keimanan yang kuat dalam keesaan Allah dan akan membantu seseorang untuk memenuhi kewajiban hidup (Jaelani, 2016).

Berdasarkan beberapa pengertian di atas, maka indikator wisata religi dalam Islam dapat disimpulkan berikut ini: 


\section{Terakreditasi Nasional Sinta 4: SK. No.30/E/KPT/2019}

a. Konsep budaya dalam kaitannya dengan pariwisata Islam (situs budaya-agama Islam) (Al-Hamarneh, 2011).

b. Pariwisata identik dengan Muslim (tunduk pada kepatuhan dengan nilai-nilai Islam), meskipun dapat diperluas yang mencakup non Muslim (Shakona, 2013).

c. Wisata religi (ziarah dan kunjungan ke tempat-tempat suci di seluruh dunia Islam) (Sanad, Kassem, \& Scott, 2010).

d. Pariwisata Islam: suatu pariwisata dengan dimensi moral baru yang didasarkan pada nilai-nilai yang dapat diterima, berdimensi etis dan memiliki standar transendental (Younis, Sundarakani, \& Vel, 2016).

e. Wisata Islam: perjalanan yang bertujuan dengan motivasi "keselamatan" atau kegiatan yang berarti berasal dari motivasi Islam (Din, 1989).

Untuk lebih jelas, seperti dirinci Khaerani et al., (2018) dalam Andriani, (2015), perbedaan antara wisata konvensional, wisata religi, dan wisata syariah atau wisata halal dapat dilihat pada tabel berikut ini:

Tabel 1. Perbedaan wisata konvensional, wisata religi, dan wisata syariah

\begin{tabular}{|c|c|c|c|c|}
\hline No. & Aspek & Wisata Konvensional & Wisata Religi & Halal Tourism \\
\hline 1. & Obyek & $\begin{array}{l}\text { Alam, budaya, } \\
\text { Heritage, Kuliner }\end{array}$ & $\begin{array}{l}\text { Tempat Ibadah, } \\
\text { Peninggalan } \\
\text { Sejarah }\end{array}$ & Semuanya \\
\hline 2. & Tujuan & Menghibur & Meningkatkan Spritualitas & $\begin{array}{l}\text { Meningkatkan spritualitas dengan } \\
\text { cara menghibur }\end{array}$ \\
\hline 3. & Target & $\begin{array}{l}\text { Aspek spiritual } \\
\text { Yang bisa } \\
\text { menenangkan jiwa. } \\
\text { Guna mencari } \\
\text { ketenangan batin }\end{array}$ & $\begin{array}{l}\text { Menyentuh kepuasan dan } \\
\text { kesenangan } \\
\text { berdimensi nafsu, semata- } \\
\text { mata hanya } \\
\text { untuk hiburan }\end{array}$ & $\begin{array}{l}\text { Memenuhi keinginan dan } \\
\text { kesenangan serta } \\
\text { menumbuhkan } \\
\text { beragama }\end{array}$ \\
\hline 4. & Guide & $\begin{array}{lr}\text { Memahami } & \text { dan } \\
\text { Menguasai } & \text { informasi } \\
\text { sehingga } & \text { bisa } \\
\text { menarik } & \text { wisatawan } \\
\text { terhadap } & \text { obyek } \\
\text { wisata } & \end{array}$ & $\begin{array}{l}\text { Menguasai sejarah tokoh } \\
\text { dan lokasi yang menjadi } \\
\text { obyek wisata }\end{array}$ & $\begin{array}{l}\text { Membuat turis tertarik pada } \\
\text { obyek sekaligus membangkitkan } \\
\text { spirit religi wisatawan. Mampu } \\
\text { menjelaskan fungsi dan peran } \\
\text { syariah dalam bentuk } \\
\text { kebahagiaan dan kepuasan batin } \\
\text { dalam kehidupan manusia. }\end{array}$ \\
\hline 5. & $\begin{array}{l}\text { Fasilitas } \\
\text { Ibadah }\end{array}$ & Sekedar pelengkap & Sekedar pelengkap & $\begin{array}{l}\text { Menjadi bagian yang menyatu } \\
\text { dengan obyek pariwisata, ritual } \\
\text { ibadah menjadi bagian paket } \\
\text { hiburan }\end{array}$ \\
\hline 6. & Kuliner & Umum & Umum & Spesifik yang halal \\
\hline 7. & $\begin{array}{l}\text { Relasi } \\
\text { Masyarakat } \\
\text { dan } \\
\text { Lingkungan }\end{array}$ & $\begin{array}{l}\text { Obyek Wisata } \\
\text { Komplementar dan } \\
\text { hanya untuk } \\
\text { keuntungan materi }\end{array}$ & $\begin{array}{l}\text { Komplementar dan } \\
\text { hanya untuk } \\
\text { keuntungan materi }\end{array}$ & $\begin{array}{l}\text { Integrated, interaksi berdasar } \\
\text { pada prinsp syariah }\end{array}$ \\
\hline 8. & $\begin{array}{l}\text { Agenda } \\
\text { Perjalanan }\end{array}$ & Setiap waktu & Waktu-waktu tertentu & Memperhatikan waktu \\
\hline
\end{tabular}

Sumber: Ngatawi al-Zaztrow dalam Andriani, (2015) 
Menurut Kementerian Pariwisata dan Ekonomi Kreatif dan Dewan Syariah Nasioal-Majelis Ulama Indonesia pariwisata syariah memiliki standar kriteria sebagai berikut (Sofyan, 2012):

a. Berorientasi untuk kemaslahatan umum.

b. Berorientasi pada penyegaran, pencerahan, dan ketenangan.

c. Menghindari khurofat dan kemusyrikan.

d. Menghindari berbuatan buruk, seperti zina, pornoaksi, pornografi, minuman keras, narkoba dan judi.

e. Menjaga perilaku, etika dan nilai luhur kemanusiaan, seperti tidak bersikap hedonis dan asusila.

f. Menjaga keamanan, amanah, dan kenyamanan.

g. Bersifat inklusif dan universal.

h. Menjaga kelestarian lingkungan.

i. Menghormati nilai-nilai sosial budaya dan kearifan.

Apabila ke sembilan kriteria di atas di implementasikan dalam usaha penyedia makanan dan minuman maka seluruh restoran, kafe, di obyek wisata halal harus terjamin kehalalan makanan yang disajikannya, sejak dari bahan baku hingga proses penyediaan bahan baku dan proses memasaknya, inilah yang namakan halal supply chain (Khaerani et al., 2018).

Global Muslim Travel Index mengidentifikasi 3 tema penilaian GMTI 2016 tentang wisata syariah yaitu (MasterCard \& Crescenrating., 2018):

a. Destinasi yang aman dan ramah untuk aktifitas liburan keluarga

1) Destinasi wisata yang ramah keluarga..

2) Kemanan secara umum maupun khusus untuk wisatawan muslim.

b. Fasilitas dan pelayanan yang ramah muslim

1) Pilihan dan jaminan kehalalan makanan.

2) Fasilitas sholat.

3) Pilihan akomodasi.

c. Pemasaran dan kesadaran destinasi tentang wisata syariah

1) Kemudahan berkomunikasi.

2) Kesadaran tentang kebutuhan wisatawan muslim dan usaha untuk memenuhinya.

3) Transportasi Udara.

4) Persyaratan Visa.

Sofyan, (2012) menjelaskan bahwa pemilihan destinasi wisata yang sesuai dengan nilai-nilai syariah Islam juga menjadi pertimbangan utama dalam mengaplikasikan konsep wisata syariah, setiap destinasi wisata yang akan dituju haruslah sesuai dengan nilai-nilai keislaman seperti memiliki fasilitas ibadah yang memadai berupa tersedianya sajadah, mukena dan sarung dengan kondisi kebersihan yang terjaga dan mencukupi kebutuhan. Beberapa aspek lainnya yang mendukung seperti; masjid ramah terhadap perempuan dan anak. Dalam rangka memenuhi 
kebutuhan muslim perempuan, masjid di desain dengan lebih banyak ruang bagi perempuan. Serta masyarakat yang saling terkait dan melengkapi terwujudnya kepariwisataan yang sesuai dengan prinsip syariah. Dibawah ini merupakan struktur MUI di Indonesia sebagaimana Gambar 1.

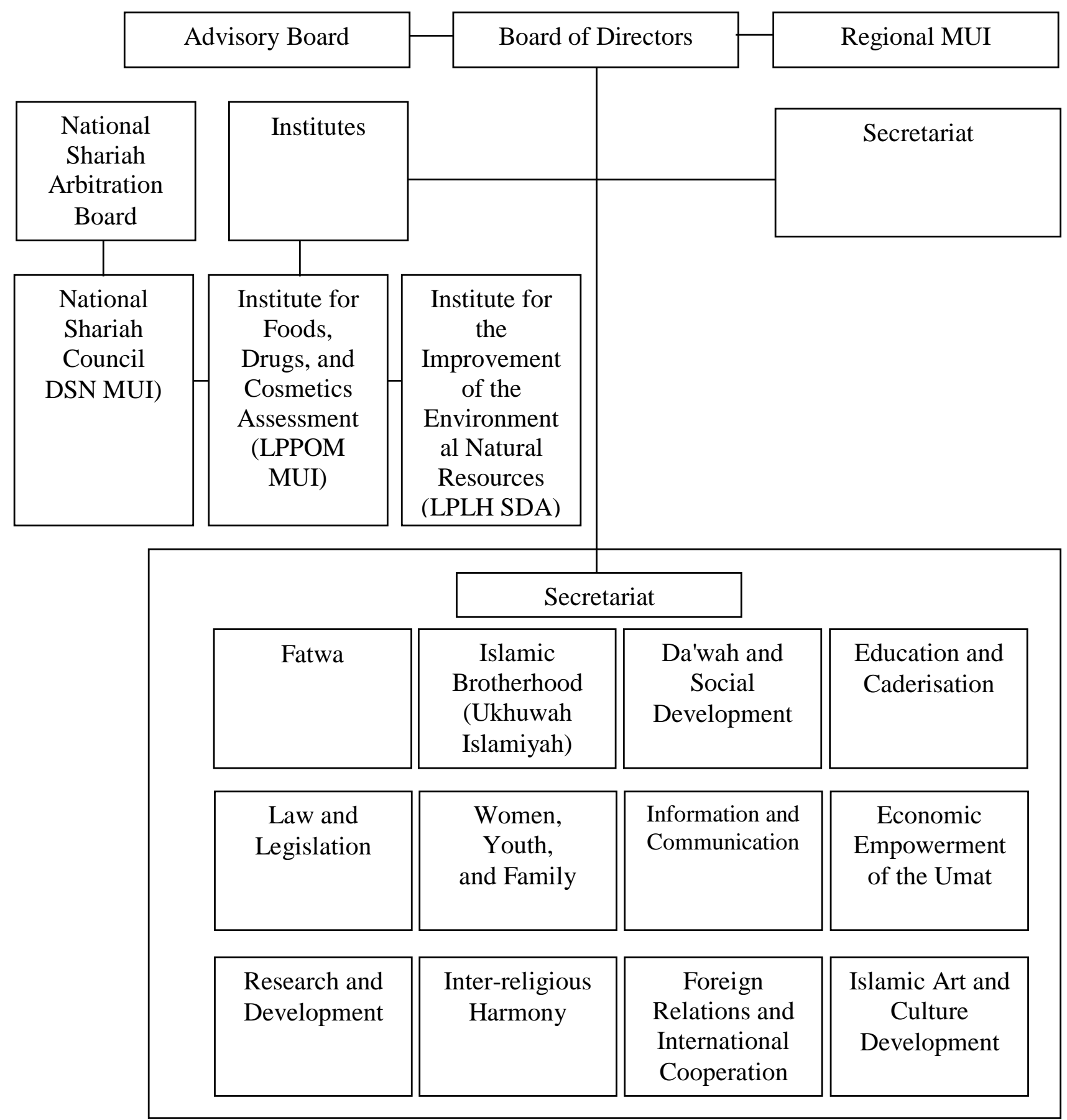

Gambar 1 : Struktur Organisasi MUI

Obyek dalam pariwisata syariah dapat berupa: wisata alam, wisata budaya, wisata religi, wisata cagar alam (taman konservasi), wisata pertanian (agrowisata) dan wisata buatan yang dibingkai dalam nilai-nilai Islam. Sebenarnya destinasi wisata 
syariah tidak bisa dispesifikkan, hanya saja wisata syariah ini sebagaimana konsep dan karakteristiknya. Didalam kegiatan wisata syariah ini harus ada fasilitas yang menunjang kebutuhan wisatawan muslim seperti: menyediakan makanan halal, fasilitas shalat, fasilitas di kamar mandi untuk berwudhu, arah kiblat di kamar hotel, informasi waktu sholat, pelayanan saat bulan ramadan, pencantuman label tidak halal untuk mengetahui produk yang tidak bisa dikonsumsi oleh muslim, dan fasilitas rekreasi yang memisahkan antara pria dan wanita. Bisa juga ditambahkan interpretasi objek wisata yang dimasukan unsur nilai-nilai islam sebagai pengingat dan renungan bagi muslim.

Mohsin, Ramli, \& Alkhulayfi, (2016) menambahkan bahwa nilai-nilai Islam yang melekat tersebut menjadikan para wisatawan dalam melakukan kagiatan wisata, di samping memperoleh kesenangan yang bersifat duniawi, juga mendapatkan kesenangan yang sejalan dengan nilai-nilai yang selaras secara dan seiring dengan tujuan dijalankannya syari'ah, yaitu memelihara kesejahteraan manusia yang mencakup perlindungan terhadap keimanan, kehidupan, akal, keturunan, dan harta benda (Samori et al., 2016) (Nizar, 2016a).

\section{Konsep Pariwisata Syariah}

Menurut Priyadi, (2016) Konsep wisata syariah adalah sebuah proses pengintegrasian nilai-nilai keisalaman kedalam seluruh kegiatan wisata. Pokok dari wisata syariah tentunya adalah pemahaman makna syariah disegala aspek kegiatan wisata mulai dari sarana penginapan, sarana transportasi, sarana makanan dan minuman, sistem keuangan, hingga fasilitas dan penyedia jasa wisata itu sendiri. Beberapa prinsip pengembangan wisata berbasis syariah mencangkup:

a. Pengembangan fasilitas wisata berbasis syariah dalam skala besar atau kecil beserta pelayanan di luar dan di dalam atau dekat lokasi wisata.

b. Fasilitas dan pelayanan berbasis syariah tersebut dimiliki dan dikerjakan oleh masyarakat setempat, yang dilakukan dengan bekerjasama atau dilakukan secara individual oleh yang memiliki.

c. Pengembangan wisata berbasis syariah didasarkan pada salah satu sifat budaya tradisional yang lekat pada suatu lingkungan religius atau sifat atraksi berbasis syariah yang dekat dengan alam dimana pengembangan lingkungan sebagai pusat pelayanan berbasis syariah bagi wisatawan yang mengunjungi kedua atraksi tersebut.

Para sahabat Nabi Muhammad menyebar ke seluruh dunia, mengajarkan kebaikan dan mengajak mereka untuk menjalankan kebenaran. Konsep wisata dikembangkan untuk mencapai tujuan tersebut. Akhirnya, wisata Islam juga termasuk kegiatan perjalanan untuk merenungkan keajaiban penciptaan Allah dan menikmati keindahan alam semesta ini, sehingga akan membuat jiwa manusia mengembangkan keimanan yang kuat dalam keesaan Allah dan akan membantu seseorang untuk memenuhi kewajiban hidup (Jaelani, 2016). 


\section{Terakreditasi Nasional Sinta 4: SK. No.30/E/KPT/2019}

Berdasarkan beberapa pengertian di atas, maka indikator wisata religi dalam Islam dapat disimpulkan berikut ini:

a. Konsep budaya dalam kaitannya dengan pariwisata Islam (situs budaya-agama Islam) (Al-Hamarneh, 2011).

b. Pariwisata identik dengan Muslim (tunduk pada kepatuhan dengan nilai-nilai Islam), meskipun dapat diperluas yang mencakup non Muslim (Shakona, 2013).

c. Wisata religi (ziarah dan kunjungan ke tempat-tempat suci di seluruh dunia Islam) (Sanad et al., 2010).

d. Pariwisata Islam: suatu pariwisata dengan dimensi moral baru yang didasarkan pada nilai-nilai yang dapat diterima, berdimensi etis dan memiliki standar transendental (Younis et al., 2016).

e. Wisata Islam: perjalanan yang bertujuan dengan motivasi "keselamatan" atau kegiatan yang berarti berasal dari motivasi Islam (Din, 1989).

Untuk lebih jelas, seperti dirinci Khaerani et al., (2018) dalam Andriani, (2015), perbedaan antara wisata konvensional, wisata religi, dan wisata syariah atau wisata halal dapat dilihat pada tabel berikut ini:

Tabel 2. Perbedaan wisata konvensional, wisata religi, dan wisata syariah

\begin{tabular}{|c|c|c|c|c|}
\hline No. & Aspek & Wisata Konvensional & Wisata Religi & Halal Tourism \\
\hline 1. & Obyek & $\begin{array}{l}\text { Alam, budaya, } \\
\text { Heritage, Kuliner }\end{array}$ & $\begin{array}{l}\text { Tempat Ibadah, } \\
\text { Peninggalan Sejarah }\end{array}$ & Semuanya \\
\hline 2. & Tujuan & Menghibur & $\begin{array}{l}\text { Meningkatkan } \\
\text { Spritualitas }\end{array}$ & $\begin{array}{l}\text { Meningkatkan spritualitas } \\
\text { dengan cara menghibur }\end{array}$ \\
\hline 3. & Target & $\begin{array}{l}\text { Aspek spiritual } \\
\text { yang bisa menenangkan } \\
\text { jiwa. Guna mencari } \\
\text { ketenangan batin }\end{array}$ & $\begin{array}{l}\text { Menyentuh kepuasan dan } \\
\text { kesenangan yang } \\
\text { berdimensi nafsu, semata- } \\
\text { mata hanya untuk hiburan }\end{array}$ & $\begin{array}{l}\text { Memenuhi keinginan dan } \\
\text { kesenangan serta } \\
\text { menumbuhkan kesadaran } \\
\text { beragama }\end{array}$ \\
\hline 4. & Guide & $\begin{array}{lr}\text { Memahami } & \text { dan } \\
\text { Menguasai } & \text { informasi } \\
\text { sehingga bisa } & \text { menarik } \\
\text { wisatawan } & \text { terhadap } \\
\text { obyek wisata } & \end{array}$ & $\begin{array}{l}\text { Menguasai sejarah tokoh dan } \\
\text { lokasi yang menjadi obyek } \\
\text { wisata }\end{array}$ & $\begin{array}{l}\text { Membuat turis tertarik pada } \\
\text { obyek sekaligus } \\
\text { membangkitkan spirit relig } \\
\text { wisatawan. Mampu } \\
\text { menjelaskan fungsi dan } \\
\text { peran syariah dalam bentuk } \\
\text { kebahagiaan dan kepuasan } \\
\text { batin dalam kehidupan } \\
\text { manusia. }\end{array}$ \\
\hline 5. & $\begin{array}{l}\text { Fasilitas } \\
\text { Ibadah }\end{array}$ & Sekedar pelengkap & Sekedar pelengkap & $\begin{array}{lrr}\text { Menjadi } & \text { bagian } & \text { yang } \\
\text { menyatu dengan } & \text { obyek } \\
\text { pariwisata, ritual ibadah } & \text { ibalian } \\
\text { menjadi bagian paket hiburan }\end{array}$ \\
\hline 6. & Kuliner & Umum & Umum & Spesifik yang halal \\
\hline 7. & $\begin{array}{l}\text { Relasi } \\
\text { Masyarakat dan } \\
\text { Lingkungan }\end{array}$ & $\begin{array}{l}\text { Obyek Wisata } \\
\text { Komplementar dan hanya } \\
\text { untuk keuntungan materi }\end{array}$ & $\begin{array}{l}\text { Komplementar dan } \\
\text { hanya untuk } \\
\text { keuntungan materi }\end{array}$ & $\begin{array}{l}\text { Integrated, interaksi berdasar } \\
\text { pada prinsp syariah }\end{array}$ \\
\hline 8. & $\begin{array}{l}\text { Agenda } \\
\text { Perjalanan }\end{array}$ & Setiap waktu & Waktu-waktu tertentu & Memperhatikan waktu \\
\hline
\end{tabular}

Sumber: Ngatawi al-Zaztrow dalam Andriani, (2015) 


\section{HASIL DAN DISKUSI}

Tujuan syariat adalah untuk kemaslahatan baik lahir maupun batin, dunia maupun akhirat. Ini menunjukkan bahwa karakter ajaran Islam menekankan pada adanya keseimbangan (tawazun) di kalangan umatnya. Seorang Muslim tidaklah dapat dibenarkan jika dalam hidupnya hanyalah mengejar kepentingan duniawi, sementara kepentingan akhiratnya diabaikan. Padahal dalam Islam, keduanya haruslah samasama mendapatkan perhatian secara berkeseimbangan. Bukankah kehidupan dunia hanyalah sesaat, karena kehidupan akhiratlah yang kekal dan abadi sebagai tempat mempertanggungjawabkan segala perbuatannya selama di dunia. Sebab itu Islam mengajarkan pula agar seorang Muslim selama hidup dunia banyak melakukan amal shaleh sebagai bekal di dalam menghadapi hidup setelah mati (Muhammad Nizar, 2017).

Selanjutnya dalam kaitan dengan destinasi Halal Tourism, sebagaimana telah disinggung sebelumnya bahwasanya wisatawan itu bagaikan tamu yang bersilaturrahim kepada sebuah keluarga. Karena itu mereka perlu dihormati kedatangannya dan dilindungi segala kepentingannya agar merasa mendapat kepuasan lahir dan batin dalam melakukan kunjungan. Di dalam filosofi budaya Jawa, penghormatan seorang tuan rumah terhadap setiap tamu yang datang tersimpul di dalam ajaran, yakni gupuh, lungguh dan suguh. Allah Swt juga berfirman dalam surat an-Nisa ayat 1:

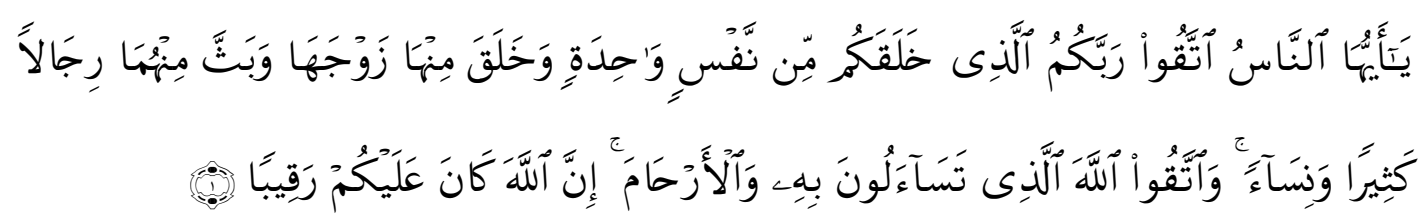

Artinya: Hai sekalian manusia, bertakwalah kepada Tuhan-mu yang telah menciptakan kamu dari seorang diri, dan dari padanya Allah menciptakan isterinya; dan dari pada keduanya Allah memperkembang biakkan laki-laki dan perempuan yang banyak. dan bertakwalah kepada Allah yang dengan (mempergunakan) nama-Nya kamu saling meminta satu sama lain, dan (peliharalah) hubungan silaturrahim. Sesungguhnya Allah selalu menjaga dan mengawasi kamu. (QS. An-Nisa': 1)

Gupuh dimaksudkan agar tuan rumah segera menyambut baik tamunya dengan penuh hormat dan ramah, setelah itu sang tamu dipersilakan duduk, dan jika memungkinkan bisa dijamu dengan sekadar makanan dan minuman seperlunya. Itulah sekadar ilustrasi yang mencoba menggambarkan, bagaimankah seharusnya destinasi wisata halal menyambut dan melayani para wisatawan yang datang agar mereka merasa mendapat kepuasaan. Atau, mereka merasa ada kesan dan daya tarik tersendiri yang pada akhirnya ada keinginan untuk menjadi pelanggan yang setia (Antin Rakhmawati, Muhammad Nizar, \& Kholid Murtadlo, 2019). 
Praktik semacam itu sejatinya samahalnya dengan apa yang diajarankan dalam Islam, yang mewajibkan setiap Muslim agar memuliakan tamunya sebagai ekspresi rasa keimanan mereka kepada Allah Swt. Selanjutnya bagaimanakah bentuk penghormatan dan pelayanan itu jika diaplikasikan ke dalam dunia wisata dalam perspektif maqashid al-syariah yang pada dasarnya mengajarkan untuk melindungi kepentingan wisatawan yang meliputi aspek: agama, jiwa, akal, keturunan, harta, dan bahkan juga lingkungan sekitarnya.

Pariwisata halal jelas beda dengan pariwisata konvensional yang selama ini telah banyak berkembang di berbagai belahan bumi. Perbedaan itu dapat dipahami dari karakteristik antarkeduanya karena berangkat dari paradigma yang berbeda pula. Pariwisata konvensional bersumbu pada paradigma materialiatik yang dapat dikatakan steril dari nuansa nilai-nilai spiritualistic (Nizar, M., \& Mashuri, 2018).

Serbaliknya, pariwisata halal yang sangat bertumpu pada paradigma rabbaniyyah, sebagaimana tercermin dari perekatan predikat halal di belakang kata pariwisata. Sebab itu Dewan Syariah Nasional Majelis Ulama Indonesia dalam fatwanya menyatakan pariwisata halal adalah pariwisata yang berdasarkan pada prinsip syariah.

Penggunaan kata "Prinsip Syariah," mengandung konsekuensi terhadap segala aktivitas yang dilakukan, tanpa kecuali aktivitas pariwisata, yakni harus mengikuti ketentuan-ketentuan Tuhan sebagaimana yang tersirat dan tersurat di dalam sumber ajarannya, yakni al-Qur'an dan Sunnah. Artinya, jika sekiranya pariwisata halal, lepas kendali dari sumber pokok ajaran ini, maka samahalnya dengan lepas dari prinsip syariah yang sejatinya wajib ditaati oleh setiap Muslim di manapun mereka berada.

Karena itu kehadiran ajaran maqashid al-syariah pada dasarnya dapat memperkuat makna halal dalam aktivitas pariwisata agar para wisatawan dalam melakukan wisata sesuai tuntunan syariah. Sekaligus ingin melindungi keyakinan mereka agar terjauh dari kemusyrikan, khurafat, kemaksiatan yang saat ini banyak terjadi dan berkembang di tengah masyarakat yang tentu saja kontraproduksi dengan yang diajarkan di dalam Islam (Jamal, 2018). Sebab itu untuk menjauhkan wisatawan Muslim dari kemaksiatan itu dalam konsep wisata halal antara lain perlu dihadirkan hotel-hotel yang bersertifikasi halal, pantai halal yang menyediakan pembatas permanen untuk turis perempuan dan laki-laki ("Wisata Halal Andalan Baru NTB," n.d.). Termasuk pula restoran-restoran yang berlabel halal agar para wisatawan Muslim tidak merasa ragu lagi mengkonsumsi setiap produk makanan, minuman, sebagaimana yang digalakkan oleh Negeri Ginseng, Korea Selatan dalam upaya menarik wisatawan Muslim yang sebanyak-banyaknya (Demeiati Kusumaningrum Nur, Aulia Mawaddah Fairuz, \& Erima Puspita, 2017).

Dengan demikian menurut perspektif ajaran maqashid al-syariah pengembangan industri pariwisata halal saat ini adalah merupakan antitesis atas praktik pariwisata konvensional yang terjauh dari norma spiritualitas yang sejatinya merupakan kebutuhan asasi bagi wisatawan Muslim secarta universal. Bukankah 
pariwisata halal itu sejatinya merupakan sarana dakwah di ruang publik untuk membumikan Islam sebagai rahmatan lil 'alamin.

Di satu sisi wisatawan dapat terpenuhi kebutuhannya untuk refreshing dan berhibur (Hermantoro, 2011) (A. Rakhmawati, Nizar, \& Rahardjo, 2019), namun di sisi lain kebutuhan ibadah (spiritual) sebagai kewajiban mereka tetap terpenuhi pula. Dalam hal ini posisi pariwisata halal, dalam perpektif maqashid al-syariah, melakukan peran sebagai pengawal akidah wisatawan. Salah satu cirinya antara lain adanya fasilitas ibadah (Chapra, 1995). Baik dalam bentuk masjid atau mushalla agar para turis Muslim tidak mengalami kesulitan dalam menunaikan kewajiban ibadahnya kepada Tuhan, kendati mereka sedang melakukan wisata (Demeiati Kusumaningrum Nur et al., 2017).

Para pelaku wisata halal memiliki tantangan dalam pengambangan usahanya. Diantaranya terdapat pengembangan usaha di sektor pariwisata yang dipandang prospektif ke depan, namun di sisi lain mereka berkomitmen untuk memfasilitasi kebutuhan wisatawan untuk tidak meninggalkan kewajibannya untuk beribadah kepada Tuhan dan mengabaikan ajaran-ajarannya. Inilah adalah gambaran yang akan menunjukkan bahwa untuk membangun sebuah industri pariwisata halal bagaimanapun harus mengedepankan karakter spesifiknya yang paling asasi, antara lain memberi perlindungan terhadap agama wisatawan sebagaimana yang diajarkan dalam maqashid al-syariah yang akan diulas lebih jauh dalam kajian berikutnya. Dalam kaitan dengan maqashid al-syariah, Ahmad Al-Mursi Husaian Jauhar, dalam sebuah kitabnya "Maqashid al-Syariah fi al-Islam" mengutip pendapat Asy-Syatibi yang membagi kemaslahatan menjadi dua kategori, baik yang pencapaiannya dengan menarik kemanfaatan atau pun menolak kemudaratan, yakni kemaslahatan dharuriyyah dan kemaslahatann ghairu dharuriyyah (Jauhar, 2010).

Kemaslahatan dharuriyyah, merupakan yang inti (pokok) sebagai dasar dan tujuan umum syariat yang mencakaup lima aspek yang harus dilindungi yang dikenal dengan istilah al-kulliyat al-khums. Sedangkan yang kedua, yang bukan pokok (bukan inti) dibagi lagi menjadi dua kategori, yakni hajji (berdasar kebutuhan) merupakan kemaslahatan yang dibutuhkan manusia untuk dapat melakukan pekerjaan dan memperbaiki kehidupan mereka, seperti sewa-menyewa, bagi hasil dan lain sebagainya. Adapun yang kedua, yakni tahsini, yakni kemaslahatan yang merujuk kepada moral dan etika yang bisa mengantar seseorang menuju muru'ah.

Muhammad Tahir Ibnu 'Ashur (W. 1973 M) membagi maqashid al-syariah menjadi dua kelompok, yakni maqashid al-tasyri' al-'ammah dan maqashid alkhashshah. Yang pertama, meliputi seluruh aspek kehidupan, sedangkan yang kedua berkaitan dengan aspek-aspek khusus, seperti bidang ekonomi, hukum keluarga (Thoriquddin, 2015). Atau maqashid al-syariah al-juz'iyyah yang meliputi setiap hukum syara' seperti kewajiban melaksanakan shalat, larangan berbuat zina dan sebagainya (Thoriquddin, 2015). Itu semua dimaksudkan untuk merealisasikan tujuan akhir dengan diaplikasikannya syariat melalui ajaran maqashid al-syariah. Untuk itu 
dalam kaitan dengan ajaran maqashid al-syariah ini Ibnu 'Ashur mendefinisikan maslahah sebagai suatu perbuatan yang dapat merealisasikan kebaikan atau kemanfaatan selamanya, baik secara umum maupun khusus (Thoriquddin, 2015).

Mashlahah 'ammah adalah kemaslahatan yang menyangkut kepentingan umum, sedangkan mashlahah khashshah adalah kemaslahatan yang menyangkut kepentingan diri sendiri (individu) (Fauzia \& Riyadi, 2014). Betapa staregisnya posisi ajaran maqashid al-syariah ini dalam penetapan masalah hukum, sehingga dengan demikian Ibnu 'Ashur menekankan betapa pentingnya seorang fukaha' menguasai ajaran ini (Fauzia \& Riyadi, 2014).

Pendapat Ibnu 'Ashur tersebut ada titik persamaannya dengan pendapat Wahbah Zuhayli (L. 1932M) yang membagi maqashid alsyariah ke dalam dua bagian, yakni pertama, yang berhubungan dengan al-mashlahah al-kulliyah (kepentingan publik) dan al-mashlahah al-juz'iyyah al-khashshah (kepentingan individu). Sedangkan yang kedua pembagian menurut kepentingan pemenuhannya dan penghindaran terhadap kerusakannya, yakni al-mashlahah alqath'iyyah (kemaslahatan yang sudah pasti), almashlahah al-dzanniyah (kemaslahatan yang tingkat kesalahannya sedikit), dan almashlalah al-wahmiyyah (kemaslahatan yang tingkat kesalahannya dominan).

Pada bagian sub ini akan dicoba dikaji bagaimanakah posisi Pariwisata Halal dalam kaitan dengan kebutuhan hidup manusia dalam kapasitasnya sebagai wisatawan. Dalam ajaran Islam, kebutuhan itu dapat dipetakan ke dalam tiga tingkatan, yakni primer (pokok-utama-dasar), sekunder (pendukung), dan tersier (pelengkap-penyempurna). Dikatakan primer, karena kebutuhan ini dalam keadaan apa pun dan di manapun harus terpenuhi agar manusia tetap bisa bertahan hidup. Contoh konkretnya adalah kebutuhan sandang, pakan, dan papan. Ini sejatinya kebutuhan pokok dan mendasar manusia yang harus terpenuhi. Jika tidak, maka manusia akan mengalami nasib fatal yang mungkin bisa mengalami kematian (Muhammad Nizar, 2017).

Selanjutnya, untuk kebutuhan sekunder, merupakan kebutuhan penunjang kemudahan dalam kehidupan. Maksudnya, dengan terpenuhinya kebutuhan ini, niscaya kehidupan manusia akan semakin mudah dijalani. Contohnya adalah kebutuhan alat transportasi dan komunikasi. Jika sekiranya kebutuhan ini dalam keadaan normal, belum terpenuhi, niscaya manusia masih bisa mempertahankan hidupnya. Tidaklah sebagaimana kebutuhan primer yang selalu harus terpenuhi.

Berikutnya kebutuhan tersier yang fungsinya adalah sebagai pelengkap kebutuhan yang lain. Namun demikian dengan tertundanya pemenuhan kebutuhan pelengkap ini kiranya tidak akan banyak berpengaruh secara signifikan terhadap irama atau stabilitas kehidupan seseorang. Katakan saja melakukan wisata, kiranya dapat dikategorikan ke dalam kebutuhan yang ketiga ini. Namun demikian perlu disadari bahwa berwisata pada hakikatnya merupakan kebutuhan psikis semua orang, karena dengan berwisata seseorang akan menambah kepuasan dalam kehidupannya. Dengan 
melalui wisata seseorang akan merasa tercerahkan pikirannya dan akan merasakan tenang batinnya (Pitana \& Gayatri, 2005).

Sebab itu dalam kaitan wisata sebagai kebutuhan batin bagi seseorang, pada akhirnya kebutuhan berwisata itu tidak lagi sebagai kebutuhan tersier, namun bisa jadi meningkat kebutuhan sekunder. Atau, bahkan sebagai kebutuhan primer yang akan merasakan lebih bahagia sesuai status sosial seseorang. Maslahat sebagai substansi dari maqashid al-syari'ah khususnya terkait wisata halal dapat dibagi sesuai dengan tinjauannya. Bila dilihat dari aspek pengaruhnya dalam kehidupan manusia, maslahad dapat dibagi menjadi tiga tingkatan Shidiq, (2009):

\section{Dharuriyat}

Dharuriyah adalah yaitu maslahat yang bersifat primer, di mana kehidupan manusia sangat tergantung padanya, baik aspek diniyah maupun aspek duniawi. Maka ini merupakan sesuatu yang tidak dapat ditinggalkan dalam kehidupan manusia. Jika itu tidak ada, kehidupan manusia di dunia menjadi hancur dan kehidupan akhirat menjadi rusak. Ini merupakan tingkatan maslahat yang paling tinggi. Di dalam Islam, maslahat dharuriyat ini dijaga dari dua sisi: pertama, realisasi dan perwujudannya, dan kedua, memelihara kelestariannya.

Karena itu kehadiran ajaran maqashid al-syariah pada dasarnya dapat memperkuat makna halal dalam aktivitas pariwisata agar para wisatawan dalam melakukan wisata sesuai tuntunan syariah. Sekaligus ingin melindungi keyakinan mereka agar terjauh dari kemusyrikan, khurafat, kemaksiatan, dan lain sebagainya yang saat ini banyak terjadi dan berkembang di tengah masyarakat yang tentu saja kontraproduksi dengan yang diajarkan di dalam Islam. Sebab itu untuk menjauhkan wisatawan Muslim dari kemaksiatan itu dalam konsep wisata halal antara lain perlu dihadirkan hotel-hotel yang bersertifikasi halal, pantai halal yang menyediakan pembatas permanen untuk turis perempuan dan laki-laki. Termasuk pula restoranrestoran yang berlabel halal agar para turis Muslim tidak merasa ragu lagi mengkonsumsi setiap produk makanan, minuman, dan lain sebagainya sebagaimana yang digalakkan oleh Negeri Ginseng, Korea Selatan dalam upaya menarik wisatawan Muslim yang sebanyak-banyaknya.

Dengan demikian menurut perspektif ajaran maqashid al-syariah pengembangan industri pariwisata halal saat ini adalah merupakan antitesis atas praktik pariwisata konvensional yang terjauh dari norma spiritualitas yang sejatinya merupakan kebutuhan asasi bagi wisatawan Muslim secarta universal.

\section{Hajiyat}

Hijiyah yaitu maslahat yang bersifat sekunder, yang diperlukan oleh manusia untuk mempermudah dalam kehidupan dan menghilangkan kesulitan maupun kesempitan. Jika ia tidak ada, akan terjadi kesulitan dan kesempitan yang implikasinya tidak sampai merusak kehidupan. Untuk memenuhi prinsip Hajiyah wisata halal harus benar-benar didorong oleh perbakan syariah, untuk meningkatkan pelayanan, baik pelayanan dari sektor pengelola atau pelayanan dari sektor pelaku UKM. Dari sisi 
sektor pengelola tentunya harus di dukung oleh fasilitas-fasilitas ibadah atau islami, seperti Masjid atau mushola, transportasi yang memisahkan wanita dengan pria, makanan yang tersertifikasi halal, sehingga ketika ada pengunjung yang hadir, bisa merasa puas, sehingga nantinya dapat menceritakan kepada sanak saudara, bahwasanya tempat yang telah dia kunjungi benar-benar bagus, dan sesuai dengan konsep Islam (Nizar, 2016b)(Nizar, 2015).

\section{Tahsiniyat}

Tahsiniyah yaitu maslahat yang merupakan tuntutan muru'ah (moral), dan itu dimaksudkan untuk kebaikan dan kemuliaan. Jika ia tidak ada, maka tidak sampai merusak ataupun menyulitkan kehidupan manusia. Maslahat tahsiniyat ini diperlukan sebagai kebutuhan tersier untuk meningkatkan kualitas kehidupan manusia. Etika dalam menjamu atau melayani wisatawan juga harus ditekankan. Karena dengan kesopanan atau etika, berarti telah memenuhi etika dalam syariah Islam.

\section{KESIMPULAN}

Dalam DSN-MUI No. 08 Tahun 2016 tentang pariwisata halal dapat dipahami bahwa bagaimanapun kehadiran pariwisata halal secara teoritik normatif butuh pendampingan terkait maqashid al-syariah, agar pelaksanaan wisata benar-benar sesuai dengan prinsip syariah. Kesesuaian aktivitas wisata halal dalam realitas di lapangan dengan norma yang terkandung di dalam maqashid al-syariah mengindikasikan bahwa wisata itu benar-benar telah menjalankan prinsip yang disyariatkan.

Bukanlah hanya sekadar kamuflase yang menyebabkan ketidakpuasan bagi wisatawan. Katakan saja, jika wisatawan Muslim berkunjung ke sebuah destinasi wisata halal, namun pada suatu saat mereka sulit mendapatkan tempat shalat, atau pun jika fasalitas itu tersedia, namun kurang memadai, maka bukanlah tidak mungkin mereka akan merasakan kekecewaan. Demikian pula jika fasilitas restoran halal yang mereka butuhkan tidak atau belum tersedia, kiranya juga berpotensi melahirkan rasa kecewa yang sama. Sekiranya ada, namun belum secara transparan mencantumkan label halal sebagaimana yang ditentukan menurut peraturan-perundangan.

Demikian pula jika faktor keamanan yang kurang terjamin yang menyebabkan para pengunjung merasa tidak aman, maka dampaknya bisa jadi sama dengan kedua fasilitas di atas. Ini semua tentu merupakan tantangan bagi pengelola destinasi wisata halal agar para wisatawan merasa nyaman dan aman sesuai yang diharapkan. Bukankah kata kunci kepuasan wisatawan berkunjung ke sebuah destinasi wiasata adalah adanya pelayanan untuk memenuhi kebutuhan wisatawan. Kebutuhan dimaksud baik yang berkaitan dengan masalah spiritual, sosial, keamanan, kenyamanan dan lain sebagainya. Dalam perspektif maqashid al-syariah, kebutuhan spiritual antara lain adalah pemenuhan fasilitas ibadah, makanan dan minuman halal. 


\section{DAFTAR PUSTAKA}

Al-Hamarneh. (2011). Islamic tourism: A long term strategy of tourist industries in the Arab world after 9/11.

Andriani, D. (2015). Laporan Awal Kajian Pengembangan Wisata Syari'ah. Jakarta: Kementerian Pariwisata RI.

Antin Rakhmawati, Muhammad Nizar, \& Kholid Murtadlo. (2019). Pengaruh Electronic Word Of Mouth (E-WWOM) dan Viral Marketing Terhadap Minat Berkunjung dan Keputusan Berkunjung. SKETSA BISNIS. https://doi.org/10.35891/jsb.v6i1.1584

Battour, M., \& Ismail, M. N. (2016). Halal tourism: Concepts, practises, challenges and future. Tourism Management Perspectives. https://doi.org/10.1016/j.tmp.2015.12.008

Bawazir, T. (2013). Panduan Praktis Wisata Syariah. Jakarta: Pustaka Al-Kautsar.

Chapra, U. M. (1995). Islam and the Economic Challenge. In Islamic Economics Series - 17.

Crescentrating. (2017). Global Muslim Travel Index (GMTI) 2017. Crescentrating.Com, (May), 1-5. https://doi.org/10.1016/j.jweia.2015.05.010

Demeiati Kusumaningrum Nur, Aulia Mawaddah Fairuz, \& Erima Puspita. (2017). Trend Pariwisata Halal Korea Selatan. Senas Pro2, 1-10. Retrieved from http://eprints.umm.ac.id/42892/18/Kusumaningrum Fairuz Putri Amalia - halal kebijakan Korea Selatan muslim pariwisata.pdf

Din, K. H. (1989). Islam and tourism. Patterns, issues, and options. Annals of Tourism Research. https://doi.org/10.1016/0160-7383(89)90008-X

Fauzia, I. Y., \& Riyadi, A. K. (2014). Prinsip Dasar Ekonomi Islam Perspektif Maqashid al-Syariah. Jakarta: Penerbit Kencana Prenadamedia Group.

Hasan Alwai (pimred) Kepala pusat Bahasa. (2003). Kamus Besar Bahasa Indonesia (Kbbi). Kementerian Pendidikan Dan Budaya.

Hermantoro, H. (2011). Creative-Based Tourism Dari Wisata Rekreatif Menuju Wisata Kreatif. Depok: Adtri.

Jaelani, A. (2016). Islamic Tourism Development in Cirebon: The Study Heritage Tourism in Islamic Economic Perspective. Journal of Economics Bibliography. https://doi.org/10.1453/jeb.v3i2.688

Jamal, N. (2018). Pariwisata Syariah Makin Berkembang, Ini Fatwa MUI Tentang Pedoman Penyelenggaraannya. Retrieved from Go Muslim website: https://www.gomuslim.co.id/read/regulasi_direktori/2018/03/17/7374/-ppariwisata-syariah-makin-berkembang-ini-fatwa-mui-tentang-pedoman- 
Terakreditasi Nasional Sinta 4: SK. No.30/E/KPT/2019

penyelenggaraannya-p-.html

Jauhar, A. A.-M. H. (2010). Maqashid Syariah. Jakarta: Amzah.

Khaerani, R., Pamungkas, P., \& Aeni, S. N. (2018). Pengembangan Daya Tarik Wisata Daarus Sunnah Menjadi Wisata Halal. Tourism Scientific Journal. https://doi.org/10.32659/tsj.v3i1.37

MasterCard, \& Crescenrating. (2018). Global Muslim Tourism Index 2015. Retrieved from http://www.crescenrating.com/mastercard-crescenrating-globalmulsimtravel-index.html

Masyfuk Zuhdi. (1987). Pengantar Hukum Syariah. Jakarta: Haji Mas Agung.

Mohamed Battour, Mohd Nazari Ismail, \& Moustafa Battor. (2012). The Mediating Role of Tourist Satisfaction: A Study of Muslim Tourists in Malaysia. Journal of Travel and Tourism Marketing, 29, 279-297. https://doi.org/10.1080/10548408.2012.666174

Mohsin, A., Ramli, N., \& Alkhulayfi, B. A. (2016). Halal tourism: Emerging opportunities. Tourism Management Perspectives. https://doi.org/10.1016/j.tmp.2015.12.010

Muhammad Nizar. (2017). Strategi Promosi Dalam Pengembangan Pariwisata Halal Di Taman Wisata Religy Gunung Mujur Karangploso Malang. Al-Ghazwah, 1(1), 87-102. Retrieved from https://jurnal.yudharta.ac.id/v2/index.php/elgozwah/article/view/589

Nizar, M., \& Mashuri, M. (2018). Pengembangan potensi lokal melalui pemberdayaan lingkungan dan umkm pada masyarakat pesisir. Soeropati, 1(1), 41-56.

Nizar, M. (2015). Strategi Pengembangan Marketing (Studi Kasus di BRPS Adil Makmur Karangploso Malang). MALIA (TERAKREDITASI), 7(1).

Nizar, M. (2016). Pengaruh Pembiayaan Mudharabah Terhadap Peningkatkan Kesejahteraan Pelaku UMKM (studi kasus BMT Maslahah Capang Pandaan). MALIA (TERAKREDITASI), 7(1), 287-310.

Nizar, M. (2016b). Proses Entrepreneurship, Kolaborasi Inovasi, Penciptaan Kekayaan di dalam Organisasi Bisnis. Jurnal Istiqro, 2(2), 91-103.

Pariwisata, K. (2012). Halal tourism industry in Indonesia: Potential and prospects. Retrieved from http://www.kemenpar.go.id/asp/detil.asp?c=16\&id=2042

Permadi, L. A., Darwini, S., Retnowati, W., Negara, I. K., \& Septiani, E. (2018). Persepsi Dan Sikap Masyarakat Terhadap Rencana Dikembangkannya Wisata Syariah (Halal Tourism) Di Provinsi Nusa Tenggara Barat. Amwaluna: Jurnal Ekonomi Dan Keuangan Syariah. https://doi.org/10.29313/amwaluna.v2i1.3275

Pilliang, Y. (2012). Masyarakat Informasi Dan Digital: Teknologi Informasi dan 
Perubahan Sosial. Jurnal Sosioteknologi.

Pitana, I. G., \& Gayatri, P. G. (2005). Sosiologi Pariwisata. Yogyakarta: Andi.

Pradja, J. S. (2012). Ekonomi Syariah. Bandung: Pustaka Setia.

Priyadi, U. (2016). Pariwisata Syariah (Prospek dan perkembangan). Yogyakarta: UPP STIM YKPN.

Rakhmawati, A., Nizar, M., \& Rahardjo, K. (2019). Green Supply Chain Management and SME's, A Qualitative Study in Indonesian Marketplace. Journal of International Conference Proceedings, 2(1).

Rakhmawati, A. R. A. (2016). Implementasi Lembaga Hisbah Dalam Meningkatkan Bisnis Islami. MALIA, 7(2), 331-334.

Salehudin, I., \& Luthfi, B. A. (2011). Marketing Impact of Halal Labeling toward Indonesian Consumer's Behavioral Intentions. Asean Marketing Journal.

Samori, Z., Md Salleh, N. Z., \& Khalid, M. M. (2016). Current trends on Halal tourism: Cases on selected Asian countries. Tourism Management Perspectives, Vol. 19, pp. 131-136. https://doi.org/10.1016/j.tmp.2015.12.011

Sanad, H. S., Kassem, A. M., \& Scott, N. (2010). Tourism and Islamic law. Bridging Tourism Theory and Practice. https://doi.org/10.1108/S20421443(2010)0000002005

Shakona, M. Y. (2013). The influence of religiosity on the intention of United States Muslim tourists to choose a shariah compliant hotel. ProQuest Dissertations and Theses. https://doi.org/10.1108/17590831011026196

Shidiq, G. (2009). Teori Maqashid Al-Syari'ah Dalam Hukum Islam. Majalah Ilmiah Sultan Agung.

Sofyan, R. (2012). Prospek Bisnis Pariwisata Syariah. Jakarta: Republika.

Syarifuddin, H. A. (2009). Ushul Fiqh. Jakarta: Kencana Prenada Media Group.

Thoriquddin, H. M. (2015). Pengelolaan Zakat Produktif Perspektif Maqashid alSyariah Ibnu 'Ashur. Malang: UIN-Maliki Press.

Wisata Halal Andalan Baru NTB. (n.d.). Jawa Pos.

Wuryanti, S., Andrijono, Susworo, \& Witjaksono, F. (2015). The Effect of High Poly Unsaturated Fatty Acid (PUFA) Dietary Supplementation on Inflammatory Status of Patients with Advanced Cervical Cancer on Radiation Treatment. Acta Medica Indonesiana.

Younis, H., Sundarakani, B., \& Vel, P. (2016). The impact of implementing green supply chain management practices on corporate performance. Competitiveness Review, 26(3), 216-245. https://doi.org/10.1108/CR-04-2015-0024 
Jurnal Istiqro: Jurnal Hukum Islam, Ekonomi dan Bisnis

Vol.6 / No.1: 95-113, Januari 2020,

ISSN : 2599-3348 (online)

ISSN : 2460-0083 (cetak)

Terakreditasi Nasional Sinta 4: SK. No.30/E/KPT/2019 